\title{
Knowledge Workers in the In-Between: Network Identities
}

\author{
By Tara Fenwick, University of Alberta \\ Knowledge Workers in the In-Between: Network Identities
}

By Tara Fenwick, University of British Columbia

\section{Structured Abstract}

Purpose

This article examines the identities and subjectivities of independent knowledge workers who contract their services to organizations. Two questions are addressed: Who are these enterprising knowledge workers, in terms of how they understand and position themselves relative to organizational structures, practices and social relations in their work as 'inside outsiders'? How do they recognize their own constitution, and what spaces for agency are possible?

Methodology/Approach

The discussion draws upon a qualitative study of 18 self-employed consultants in organizational change, analysing their articulations of subjectivity as ongoing constitutions within prescribed discourses and cultural technologies. Semi-structured in-depth interviews were analysed inductively to determine themes and silences among the narratives.

\section{Findings}

The argument shows how these subjectivities emerge from in-between spaces, both inside and outside organizations. As they negotiate these spaces, they exercise agency by resisting control while building connections. These articulations are described as 'network identities'.

\section{Practical Implications}

The article concludes with implications for organizations employing or contracting with such individuals. Suggestions for managers involve enabling more project structures, negotiating boundaries and purposes more clearly, providing more flexible conditions and facilitating more integration of these knowledge workers with other employees before, during and following innovative project activity.

Keywords: subjectivity, knowledge workers, contract workers, enterprising self

\section{Introduction}

With massive organizational restructuring in the 1990s in North America and the consequent shuffling and even dissolution of jobs in the professional/middle managerial ranks, many knowledge workers left organizations to become self-employed. These self-employed workers have been described variously as consultants, contractors, freelancers, independent professionals, "itinerant experts" (Barley and Kunda, 2004) even "boundaryless workers" or "portfolio 
workers": popular writers such as Arthur and Rousseau (2000) maintain they are revolutionising employment arrangements. While this may be overstating the case, numbers of self-employed workers certainly appear to be rising in North America, Europe and the UK. In Canada for example, Hughes (2001) reports that self-employment rose sharply in the 1990s and has continued to rise steadily since: $15 \%$ of all Canadian workers are now self-employed (Industry Canada, 2006).

At the same time, commentators have drawn attention to the ascendancy of enterprise as an organizing principle within bureaucracies, which has restructured the nature of work within organizations and thrown new emphasis on reflexivity as individuals find themselves compelled to develop identities as innovative, risk-taking entrepreneurial selves (du Gay, 2004; Storey, Salaman \& Platman, 2005). Barley and Kunda (2004) argue that the rise in contract-based employment is due to a myriad of pressures and expectations, not simply demands for flexibility, that guide every actor's decisions. What constitutes their 'knowledge' is particularly complex. As Alvesson (2001) points out, knowledge workers tend to use uncertain, shifting knowledge that is essentially ambiguous in its content, significance, and results. This ambiguity, argues Alvesson, leads to the centrality of securing and regulating identity among knowledge workers. In fact identity - its influences and processes of manufacture - has become an important site for scrutiny to understand not only particular challenges confronting contract workers, but also the changing configurations of knowledge that they both inhabit and enact in organizational conditions of flexible work (Alvesson, 2001; Barley and Kunda, 2004; Chappell et al., 2004; Fenwick, 2004).

The work structures of these contractors tend to have in common four main characteristics: (1) their work is typically project-based, defined by individual bounded contracts of varying periods for varying activities; (2) they contract their knowledge services to a variety of employers, including organizations and single clients; (3) they often juggle multiple projects and contracts simultaneously; and (4) they remain self-employed and rarely hire other employees except as limited contracts to assist with particular projects or maintenance services such as their own accounting (Fenwick, 2004). Some of the more exuberant studies of these independent, enterprising knowledge workers have suggested that they are mobile and active in designing their careers, exhilarated, able to enjoy personal meaning and personal responsibility for their work (Sullivan, 1999), while contributing to continuous knowledge production (Bird, 1996). Because such independent workers tend to form multiple networks, argue Gee, Hull and Lankshear (1996), they enable wide distribution of learning across social groups and institutions. They supposedly project a positive social vision comprising multiple nodes of learning, and multiple connections among people, tools and environments created through the unconstrained knowledge and unbound identities of boundaryless labour (Gee et al., 1996). Others such as Alvesson (2001) have provided a more 'suspicious' perspective, showing that their knowledge tends to rely most upon image impression, rhetorical intensity, and social connections, leading to a shakiness and vulnerability that makes it difficult to secure and regulate identity.

Particular interest has centred on these workers' career identity. How individuals "construct nonorganisationally sustained accounts of their working lives" is a focus for Gold and Fraser (2002, p.583), who examined independent workers' strategies for successful transition. While remaining outsiders to their employing organizations, their contracted projects require them to infiltrate and 
become immersed in the networks of relations and practices within the organization, becoming temporary insiders (Fenwick, 2003). Yet this is a delicate position, for both they as well as the regular employees recognize that the independent knowledge worker always remains external, and is granted certain privileges and freedoms along with exclusions that other employees do not experience. Thus the independent knowledge worker occupies an 'in-between' space: neither a separate enterprise apart from the organization, nor an integrated part of the organization, even temporarily.

From an organizational point of view, these independently-oriented knowledge workers are attractive as they tend to be enterprising flexible workers who thrive on challenge and initiative. For organizations, then, two questions are of interest in examining this phenomenon. Who are these enterprising knowledge workers, in terms of how they understand and position themselves relative to organizational structures, practices and social relations in their work as 'inside outsiders'? How do they recognize their own constitution, and what spaces for agency are possible? These are questions of identity and subjectivity. Certain rather pessimistic accounts of governmentality in the workplace (e.g., Rose 1998) suggest that worker identities have been shaped by contemporary discourses of flexibility, enterprise and self-reliance in ways that govern their very attachments and desires to produce particular subjects required by contemporary organizations. However, other accounts (e.g. Chappell, et al. 2004; Davies, 2000; Hey 2002) contest this rather deterministic reading. They show, through detailed readings of workers' negotiations of material and discursive practices in organizations, that these workers exercise agency and manage their various identities to create spaces for freedom, autonomy and security. In the case of self-employed knowledge workers, these exercises of subjectivity are intimately linked to their relationships and knowledge services that constitute their work. Barley and Kunda (2004) show that contractors must constantly manage what they know and who they know to survive in the market: a labour of managing one's self, knowledge, and social capital.

This article addresses these questions by presenting a recent qualitative study of knowledge workers who left organizational employment to pursue independent careers in organizational change. What is particularly interesting is that while all of these individuals profess the enterprising, innovative characteristics of entrepreneurial identities, none turned to entrepreneurship until after many years among the rank-and-file of organizational employment. Even when they did make the break to self-employment, they structured their career as individuals working with and through other organizations, rather than setting out to build their own organization of employees and production. Their contracts with organizations revolve around their knowledge which is tied up with their exercises of and influences upon their subjectivit(ies), which in turn is closely integrated with their positions, relations and practices within organizations. For these reasons, an appreciation of these dynamics of subjectivity from the perspective of independent knowledge workers is important for managers in organizations relying on their knowledge provision. The article closes with specific implications for managers drawn from the study findings.

\section{Subjectivity and Knowledge Work}

The questions at issue here have to do with what subjectivities are created in this independent work, and what processes are involved in their constitution. And what is a subject? The view 
adopted here is consistent with poststructural perspectives, that step away from binaries of the individual as separate from the collective to understand the subject as discursively constituted, malleable, and positioned at the intersection of libidinal forces and sociocultural practices (Davies, 2000; Hey, 2002). In this view there is no central authentic 'self' who goes forth with agency and intentionality to author a life of meaning and accomplishment; there are no transcendental centres of consciousness, competence, or freedom. As Butler $(1992$, p. 13) writes, the "subject is neither a ground nor a product, but the permanent possibility of a certain resignifying process." That is, the subject is an opening in the everyday flux of practices, discourses and symbols - seemingly sewn shut in a path-dependent flow - an opening for unexpected action. This action is of course infused with, even predicated upon, the available repertoire of strategies and meanings (including available images of identity), but until it occurs it remains a possibility: there is suspense, hope, and possible surprise in the unpredictable uptake that represents the movement of the individual.

In this possibility, in this ongoing constitution, lies the agency of the subject. Quite unlike conceptions of agency as an individual's internal resource fashioned as will, intention and capacity to act, Davies (2004) suggests reading agency as "the capacity to recognise that constitution and to resist, subvert and change the discourses themselves through which one is being constituted" (p.4). Agency, in such a definition, comes from a person's freedom to recognise multiple openings such that no discursive practice, or positioning within it by powerful others, can capture and control one's identity. In this view, autonomy is "the recognition of counterpower and counterforce within power and force, and the awareness of new life forms capable of disrupting or even overwriting hegemonic forms" (Davies, 2004, p. 4). Such a view departs completely from views of autonomy bound up with individuation, identity-formation, or emancipation from social 'structures'. Instead, this poststructural notion of autonomy focuses on the question of just how individuals recognize the multiple forces in which they participate, become aware of new life forms, take up existing practices and images while resisting others all in a process of exercising some freedom within the ongoing constitution and reconstitution of one's subjectivity.

This process is not about finding or creating a 'self'. 'Subjectivity' is not about 'the self' in this discussion; nor is subjectivity synonymous with identity. Identity is an image, a symbolic code representing something the subject desires to belong to or possess, to identify with. The subject strives to perform an identity or various identities. Identity is ultimately a representation or mental conception that we ascribe to ourselves and to others: our conception of who we are, our identity, is constituted by the power of all of the discursive practices in which we speak - which in turn 'speak' us (Chappell, Rhodes, Solomon, Tennant \& Yates, 2003, p. 41) [italics added]

Some suggest that the striving to perform this or that identity, compelled by desire for identification with an object, position, community or ideal, is driven by a ubiquitous lack of identity. Further, in the human desire for unity, stability and continuity, we invent a monolithic, coherent even sedentary story of 'self', a Me, based on our consciousness and remembrance of identities we have inhabited and performed. Taylor (1989) links this drive with a desire to define and reach the good based on moral ideals of self-mastery and self-control. The result is a turn to reflexivity: 
The turn to oneself is now also and inescapably a turn to oneself in the first person perspective - a turn to the self as self. That is what I mean by radical reflexivity. Because we are so deeply embedded in it, we cannot but search for reflexive language (Taylor, 1989, p. 175)

This turn to the 'self', with accompanying practices of self-improvement and self-control, energised by a drive for identity, is increasingly viewed as an important phenomenon by researchers of flexible work. Drawing from Giddens' theory of reflexive selves, Brocklehurst (2003) argues that independent or 'boundaryless' work drives people to try to create a concrete and anchored self. This attempt at self-construction is often knit with creating a firmer sense of place: when geographic organisational boundaries are removed individuals try to fix other boundaries that they perceive will enable their very existence.

Yet in its enactment the subject is always in motion, and constantly produced in time and space. Subjectivity has no existence, per se: it cannot be fixed and identified as a continuous self, but is continually constituted and resignified. The subject is derived from and subjugated to practices and cultural discourses, including practices of identification and images of identity available in the (limited phallogocentric) cultural discourses. It is conjured into presence and then moves according to how it is positioned in joint activity, its encounters with others, and the gaze of these others - as well as the limits and desires of its own corporeality (Thrift and Pile, 1995). Always subjectivity is produced by power and acted on by power. And usually the subject exercises power, sometimes to resist the very power that is shaping it, but always from within the socio-psychic forces and resources that constitute it.

In the accelerated global competition and increasing flexible employment conditions of the new capitalism, these meanings are hardly benign. Rose (1998) analysed the new subject of work as "a complex territory to explored, understood and regulated" (p.56) through "engaging the employee with the goals of the company at the level of his or her subjectivity" (p.56). This notion of governed subjects derives from one particular Foucauldian concept, which explained the individual's constitution as largely an effect of 'technologies of the self' (Foucault, 1988), cultural discourses internalized as self-regulatory mechanisms by the individual:

One of the first effects of power is that it allows bodies, gestures, discourses, and desires to be identified and constituted as something individual. The individual is not, in other words, power's opposite number; the individual is one of power's first effects. The individual is in fact a power-effect, and at the same time, and to the extent that he [sic] is a power-effect, the individual is a relay: power passes through the individuals it has constituted. (Foucault, 2003 p. 30)

In such a view, individuals regulate their own subjectivities through technologies such as career discourses, modeled images of the good worker/learner, surveillance, mentoring and other explicit guidances within particular social and political contexts. These are wedded to individuals' own desires for control, belonging, and so forth to produce their desires to become particular subjects desired by the organisation. Thus subjection to production and efficiency continues but through complex psychological means governing how subjects move, speak and manage their own movements and speech. In an age celebrating entrepreneurial, risk-taking, self- 
responsible workers, the new subjectivities are expected to pursue meaningful work and autonomous careers through 'choices' in a biographical project of self-actualisation.

However, those who contest this formulation argue that subjectivation is the process by which one becomes an acting, self-creating subject in work, achieved through the will to act and be recognised as an actor (Casey 2003, p. 629). In a study of mentorship, potentially a disciplinary process producing particular subjects, Devos (2005) found instead a very active self-constituting subject in work, whose capacity to exercise political and moral agency emerges within the very social, historical and cultural practices and relationships that constitute it. In a study of how freelance media workers position and make sense of self and subjectivity, Storey, Salaman and Platman (2005) show the strategies workers adopted to respond to enterprising discourses and power assymetries in the market. These authors employ an analytical approach drawing from Giddens and Alvesson and Wilmott, delineating three stages in the construction of identity: identity regulation or external attempts to shape identity, identity work by the individual, and self identity: the latter consists of "precarious and relatively unstable and shifting narratives of the self (Storey et al., 2005, p. 1037). Overall, they found that independent workers both actively disciplined and protected their identities, using notions of enterprise to judge themselves and their success/failures, and also to protect their identity when experiencing rejection, declining income or sense of mastery. Alvesson (2001) argues that the ambiguity of knowledge among such workers leads to space for innovative constructions of identity.

This sort of close analysis begins to reveal that while work identities and their strategies of construction are generated through organizational, cultural and market discourses, individuals actively exercise these strategies in idiosyncratic ways to constitute their everyday subjectivities - ever mobile and contingent. To avoid sliding back into that seductive notion of subject as the heroically agentic autonomous self, we need to examine more closely the interaction of subjectivity, agency and action. Zizek (1999) conceives subjectivity within the continuous flux of action without dissolving the subject's political agency. Drawing from Hegel, Badiou, Althusser, Butler and Lacan, Zizek shows that the disparate chaotic flux of reality becomes events, meaningful actions, and possibilities - a "positive objective order" - precisely through the intervention of the subject:

The 'subject' is the act, the decision by means of which we pass from positivity of the given multitude to the Truth-Event and/or to Hegemony . . . 'Subject' is not a name for the gap of freedom and contingency that infringes upon the ontological order, active in its interstices; rather, 'subject' is the contingency that grounds the very positive ontological order, that is, the vanishing 'mediator' whose self-effacing gesture transforms the preontological chaotic multitude into the semblance of a positive 'objective' order of reality (Zizek, 1999, p. 158) ${ }^{1}$

In this gesture, this act, the subject also comes into presence. Zizek cautions that this conception does not presume an ontological gap of contingency waiting to be filled by the subject's action. Rather, "the subject is both the opening or Void which precedes the gesture of subjectivisation,

\footnotetext{
${ }^{1}$ Thus neither hegemony nor truth derive directly from any ontological set, but depend on the subject's action. A 'Truth-Event' is precise political experience bearing (signifiable and ideological) Truth for those engaged in it. Multitude may be considered the chaotic excess of the situation(s) from which the experience derives.
} 
as well as the gesture itself.... the subject's very endeavour to fill in the gap retroactively sustains and generates this gap" (p. 159).

Hence, subjectivity becomes a space of possibilities. A subject is realised at the same time as a recogniseable event. This realisation occurs through the subject's act or choice intervening in the multitude of symbols, technologies, ideas and activity available in that moment. This choice does not originate from outside this multitude but is made available from a range of possibilities within it: from the tightly prescribed and oppressive, to the subversive and resistant. Power presumes counter-power. The subject's agency, the freedom that can be exercised within the action choice birthed in an event, is the recognition and articulation of possibilities that can rupture preceding hegemonies and sealed significations to engender the unexpected, the creative, the emergent. Questions of most interest to researchers exploring this subjectivity and agency in work include: How do people recognize and understand the constitution of their subjectivity, their articulations of different identities at work? How do they endeavor to resist, subject and change the discourses within which they are being constituted? What different positions do they take up within these discourses?

\section{Study Methods}

The study grounding this discussion of subjectivity in independent knowledge work set out to explore the unique rewards and challenges of this work through the narrated experiences of selfemployed individuals who contract their services to various organisations and clients. In-depth interviews were conducted in 2002-2003 with a total of 31 men and women based in large urban Canadian cities representing west coast, prairies, and central Canada. The study used conventional methods of semi-structured interviews which were taped and fully transcribed, then validated with participants. Participants were asked to describe forms of work and their reasons for entering self-employment, their approaches to creating relationships with clients and designing the work project, their challenges and strategies of working with organizations as an independent knowledge worker. Transcript analysis was inductive and interpretive, identifying common themes and disjunctures across the participant narratives. Two groups of participants were convened in follow up online dialogues to validate emerging themes and issues identified through the analysis process.

This article will focus on 18 of these individuals whose contracted knowledge work focused on facilitating organizational change. They began their careers as health care workers, educators, human resource professionals, communications specialists, systems analysts and information technologists in small and large organisations. All had completed at least ten years of organizational employment usually enjoying progressive responsibilities and scope of authority before changing to self-employment. All had been self-employed for at least four years at the time of interviews. Their contracted work embraced a range of consultative activities related to organizational change and development: training and development, program design and evaluation, management and team coaching, and change implementation. All enjoyed at least a moderately comfortable income, and were 'mid-life' ranging in age from late-thirties to midfifties. Most were well educated: all held baccalaureate degrees, all but two held master's degrees, and two held doctoral degrees. Thus most participants enjoyed a degree of mobility and social and cultural capital. 
All participants claimed that they had freely chosen to shift to independent employment arrangements (Fenwick, 2004). Their reasons are consistent with those described in selfemployment literature, including 'push' motives (frustration with repressive organisational structures or difficulty finding full-time employment in their preferred practice), 'pull' motives (desires for flexible work schedules, freedom from supervision, or urge to create a personal practice), or a push-pull combination (Cohen and Mallon, 1999). However, it is by now wellrecognised that the notion of 'choice' is problematic, and may more accurately represent received cultural discourses emphasising individuals' responsibility for their own conditions than an individual's exercise of agency. Even though some of the interviewees here may have believed they freely chose to leave employment, they may in fact have had little choice in cases where work conditions were intolerable, no full-time work was available, or future staff cuts were inevitable.

\section{Findings: Negotiating Subjectivity in the In-between}

A consistent motif across all participants' narratives was awareness of their subjectivity being constituted in and as their activity of bringing knowledge to organizations: their identities are the knowledge that is mobilized in the work. This knowledge is often imbued with moral purpose and a sense of integrity and meaningful work. As one explained,

I don't really sell services, I bring myself to the organization. Like I truly have my own vision and mission statement and it's around organizations being really human places to be, and that we get productive for sure but it's through using people's potential, not at the expense of people. .... Integrity and meaningful work and doing my work in a meaningful way is really an anchor for me and so I envisioned change in a way that made sense to me. (MM, 11. 692-95).

What is striking about this statement, besides the melding of identity ("myself") with the knowledge service, is the foregrounding of values and the strong assertion of an agentic "I" exercising these values as both the core of the knowledge work and the core "anchor" of the "me" or self. Yet they seemed to resist anchoring processes involving control such as managerial or evaluative activities, integrating or institutionalizing knowledge to help it become routine in a group. Their descriptions of knowledge tended to remain at the level of creating and innovating, as though other forms and processes of knowledge generation were not as interesting or valuable to them. So at the same time as they sought this identity anchor, participants shared a restlessness, a desire for novelty and challenge and a "high need" for continuous change (LH, 11. 293). Feelings of boredom set in with too much repetition or routine work:

.... bit suffocating, kind of like being buried alive (ST, 11. 23)

I get bored with things very quickly. So as soon as I feel I've mastered them or figured them out I want to move on....I need to be on a steep learning curve. (TD, 11. 409-14). If I'm learning, it's ok, but if I'm not learning... or if it's a tough team or an ineffective team, then you couldn't pay me $\$ 10,000$ a day. (LH, 11. 590-92)

Partly, this may stem from their capacity and preference, as independent contractors, to design much of their work: "the gains are mental gains, emotional gains... interesting work... a collage of things, and I pick that collage. I can choose a bit more who I work with... I get to say no ... I like the lack of control over me" (ST, 11. 145-50). Part of it stems from what they describe as the 
stimulation of the innovative process, seeding new ideas, and a dislike for the management processes required by implementation over the long term: "I really get a kick out of creative problem solving and coming up with a first, something that's unique" (WC, 11. 395-97); "I don't want to be in that corporate crap anymore" (GM, 11. 95-96); "Managing people is an energy waster for me" (ST, 11.678). Yet while managerial activities of coordination and control are denigrated, managing clients in an expert-client relation is not, as one anonymous reviewer helpfully pointed out. Remaining positioned in-between an isolated space of innovation outside, and the everyday complexities requiring routine and control inside the organization, allows these individuals to play out a subjectivity balanced on the edge between ground and flight.

These motifs of both anchoring and restlessness in the constitution of subjectivity in and as a particular form of knowledge work play out in various themes emerging in the narratives of these organizational change consultants. Two themes in these negotiations have been selected for further exploration here: working the in-between space (as both insider and outsider to the organizational employer) and resisting control within connections. These themes were identified through inductive analysis of the participant transcripts.

\section{Working the in-between space}

As described earlier, the 'in-between space' here refers to a discursive and relational space occupied by the independent knowledge worker that is neither inside nor outside the organization. As a non-employee, this worker is apart from the organizational social networks and cultural norms, and is not enmeshed in the everyday joint activity that comprises organizational practices. But as the 'organizational expert' contracted precisely to become enmeshed quickly within the organization's knowledge and relations, the independent knowledge worker is not an outsider, either: "They want you to be part of their small group. . They don't want you to come in and deliver something and go out and be apart from, they want you to be a part of" (LH, 11. 135-37). This ambivalence played out in being treated differently at different times. The contractor shares days of intense and intimate planning sessions with employees, after which they go out to celebrate then go back to their regular activities: "there is no more lonelier feeling in the world" (FJ, 11.) Or the contractor works alongside employees for weeks, endeavouring to champion their knowledge above all, but is still treated by management as having 'special' knowledge that others do not which is worth more because it is 'outside'.

Far from resenting this ambivalent space, however, independent knowledge workers appear to appreciate its possibilities: "I have so many communities that when I disconnect I like to be alone. So independent within a team really works well for me"; (LH, 1l 274-75); "I like long-term projects ... from a distance" (GM, 11 217-20). First, they liked the distance from organizational "politics", the daily competitive manoeuvrings for resources and position. Second, they enjoyed some freedom from historical organizational practices and prescribed organizational procedures: while respecting the limits of structures, independent knowledge workers were not shaped by them. They could focus more on what was occurring in the moment:

We didn't feel as constrained by whatever the frame was that might require some people who ... are needing to have things prepared and processed ahead of time and whatever that's all about, ...for contract workers it was more created in the moment. So - at this particular period of time, for this particular audience. (MM, 11. 131-33) 
Because they traversed many organizations and communities of practice, and because they were constantly reading to keep up with the different and changing knowledge domains in which they needed to practice, these independent workers could draw upon varied ideas and models. This allowed them to think differently when they approached problems alongside organizational employees: "I think if you're part of a system sometimes you're part of the problem. As an external person you bring in a perspective that maybe the others need to hear" (LH, 11 262-64). The freedom of their inside outsider status, many emphasized, also allowed them to say things that employees might self-censor for reasons of long-term consequences:

I ask the question that people want [to but cannot] ask themselves, and being an outside consultant you have that luxury ... it's my responsibility to affect change within but really ... as an external person I see my job even more in terms of planting the seed and assisting them to take responsibility. (KT, 11 319-24)

In working this space, independent knowledge workers walk a fine line in asking the tough questions that organizations hire them for, without crossing sacred lines of organizational authorities and undiscussables. For example, independent contractors say that they often see from the beginning when a project for which they are being hired is poorly conceived or grossly shortchanged in resources and time, but they must proceed delicately to determine how to shift management's thinking without jeopardizing the contract or their reputation. This negotiation is nothing new to consulting firms, but an independent contractor lacks the weight of constructed power and knowledge authority often wielded by an international firm. Once 'inside', contractors must continually scope out employees' changing reactions to their own questions and ideas sometimes submerging themselves and planting an idea seed in such a way that employees develop it themselves. Employees know the contractor is paid at a higher daily wage than they receive for similar work, and may observe the contractor treated as 'the second coming' by management.

Independent knowledge workers also negotiate their own identity investment in projects. As MM said, the "anchor" is "integrity and meaningful work": "I bring myself to the organization". Yet they eventually leave the project and the organization altogether, with the hope that the work they started in organizational change will be taken up by management and employees. This is sometimes a thin hope - it is well known that many consulting efforts are one-shot temporary efforts that never become integrated into organizational life. So while this ability to leave provides the independent knowledge worker a "distance" from the politics and employee management that so many dislike, it also endangers their ability to derive meaning and personal worth from their work:

The good news about being a contractor worker is you can do your work and you don't own all those other pieces and you can go home again! But the bad news is that you're not connected to all those other pieces and I think there's a danger that your work really doesn't have much impact. So they can hire you, you can come, you can do something, they can ignore you. (MM, 11 409-12)

This ultimately comes down to identity work, not just in negotiating one's subject position within and without the organization, but coming to terms with the inherent fluidity of self and knowledge that this entails. One who had only been contracting for two years (compared to MM, 
who had been independent for 11 years), admitted: "I've been searching to find out where I belong" (KT, 11. 433). Another was delighted to hear herself enunciate her identity:

I can remember the moment when I was in an elevator being introduced to someone and I actually shook their hand and said, when they said what do you do, 'I'm an organizational development consultant and I have my own business.' I remember thinking, Holy shit! that sounded so impressive, and I don't know what got me there (GM 11. 949-54).

For most, a key dynamic in working the in-between space of this knowledge work was establishing this security of a well-connected identity invested in relationships that generate knowledge, while resisting the control exercised by these relationships.

\section{Resisting control within connections}

Narratives recalling their former employment as organizational employees are instructive in understanding independent workers' need for control over their own work, and resistance to others' control. Organizational control is perceived as a "suffocating" environment, "dealing with barriers, stopping some of the opportunities" (ST, 11. 107-8). Interviewees told stories of petty tyrants: "I had a kind of boss who was more intrusive, obnoxious, bully-like" (GM, 11.14243). They disliked policy restrictions that they felt to be petty, such as dress codes. Some complained about structures and people not open to innovation, and endless meetings that accomplished little. Several indicated feeling a "values disconnection" with managers pursuing directions they felt to be unethical or that lacked meaningful purpose.

Yet as independent knowledge workers they sought to insert themselves temporarily in organizations presumably struggling with the same rigid structures, petty politics and glacial responses that had frustrated them as employees. So, while they continued to resist organizational control, they designed their work in such a way that intimately connected them with this control. There is some indication that these individuals are attracted to others' control structures, in a way that is different to entrepreneurs who go off to build their own organizational structures and design their own products. For example, MM articulates how the organizational controls that can be suffocating to employees actually helps focus her innovative process within the organization:

I always want to know what the givens are too - so tell me what they are and we'll work with those. ...I really want to know intention and I really want to know what we're trying to accomplish and what is critical so that it doesn't morph into something else. Those things are all important to me. And then I want the freedom to create within that. (MM, 11.212-15)

The 'freedom to create within' seems to be the key to understanding resistance to control. Clear boundaries, both those that are given and those that are negotiated, are not perceived as controls when they remain inert - as container walls within and around which the contractor can work. Independent knowledge workers are always negotiating with organizations the boundaries defining their actual activity, people, location, responsibilities, timelines and deliverables of their work (Fenwick, 2003). When these boundaries start to move, they are perceived to inhibit the fluid flow of knowledge, social relations and ideas that independent contractors value. They threaten control, which the contractor resists: 
I worked with people that I really trusted and that had a tremendous amount of integrity and that I really valued and we were doing some really exciting work and, and then some of the leadership changed and, and it wasn't working for me....I wasn't being given the same level of independence and I just thought, you know what? I don't need this anymore. (GM, 11 100-105)

In negotiating boundaries of the work, independent knowledge workers appear able to exercise control. They turn down projects that they believe are not viable or have questionable purposes (such as a government department wanting to complete a small project that would accomplish little but would create "optics" of action). Some, depending on personal confidence and security of their business, are openly critical with potential clients about a project's design: "People call me and they ask me to do the strangest things... Like, why would we do that??" (MM, 11. 69698). This resistance to particular project purposes or designs seems often connected with personal values determining what work is worthwhile. Stories about this were told with some relish, as though for these individuals, the capacity and opportunity to exercise such values in choosing or refusing work activity was particularly satisfying:

It became very apparent that my values and principal were really critical... 'You know,' I said, 'This is great if this is what you want to do but just know that if you do it you're opening a can of worms and if you're doing it you need to go the distance because it's not fair to others.' (KT, 11 388-90).

The other main area of resisting control is in client demands. The nature of these struggles with client organizations over what are reasonable expectations appears to vary widely depending on the size and resources of an organization, its experience working with contractors, its past relationship with a particular contractor, and the contractor's own disposition, demeanour, years of experience, power of position and knowledge relative to the organization. However, most independent knowledge workers note their clients' tendencies to expect a contractor's full commitment to and accommodation of client needs:

I've had to set some boundaries with clients and with myself where historically ... I would make myself available whenever they wanted or needed me, wanting to accommodate the clients in terms of what the client wanted and needed. (KT, 11 242-44)

I had a call recently and someone wanted something like a week later, which was completely inappropriate. And I was going away and I thought, I could change my plans. And I thought, no. I don't want to change my plans, and this isn't long enough notice. (GM, 11. 408-416).

This process of learning to set boundaries that exercise control while building strong connections is a central tension in independent knowledge work.

I'm always out there looking for connections between communities and kind of living on the edge all the time (LH, 11 285-86)

Here LH was describing how she often bid on a contract opportunity in her field of health service evaluation with little more than a beginning good idea, then mobilized connections among groups within the university, government, community agencies, health care system and 
evaluation associations to conduct the activities. In fact for most contractors interviewed in this study, connection defines their identity:

I link parts of the organization to itself . . I'm interested in bringing systems thinking and kind of personal awareness, building...the link between the broad perspective and who we are individually (DS, 11. 20-24)

I'm a linker. As an outsider you can see the connections, you can link one part of the organisation to another' (MM, adult educator, 11.444-45).

\section{Discussion: Network Identities}

Independent knowledge workers describe themselves and their work as immersed in processes of connection: connecting organizations to other groups and ideas, connecting people across organizations, connecting the personal to the systemic, and connecting themselves and their values to the organization's nets of action and purposes. In negotiating these connections, contractors could be understood to enact network identities. That is, their presence or image of personal identity appears to them in the act of connecting and mobilizing networks of actors and knowledge. They see themselves as a connector or link, but a link does not exist until the agents to be linked emerge. To recall Zizek (1999), the contractors' intervention causes both themselves and the agents to come into presence, through "the act, the decision by means of which we pass from positivity of the given multitude to the Truth-Event": here, an act of connection.

As this 'connection', their subjectivity is constituted by organizational/cultural discourses and regulated through orthodoxies about what comprises organizational change, as well as through technologies such as contract arrangements and intense scrutiny of their performance in the project. They are also self-regulated through particular desires, such as to remain intimately connected with organizations while attaining the sense of personal independence and distance accorded to the enterprising self of neoliberal capitalism.

Yet despite their clear subjection to these discourses and technologies within which emerge their actions, knowledge and identities as 'connectors', these independent knowledge workers exercise agency in the sense described by Davies (2004). They recognise their own constitution and resist and subvert the discourses themselves through which they are being constituted, such as in negotiating boundaries defining their work and relationships, rejecting work they consider purposeless, and resisting control of their action by insider politics or "intrusive" managers. At the same time, their in-between work space, neither inside nor outside the organization, allows them to recognize and leverage the "counterpower and counterforce within power and force" that Davies (2004) treats as autonomy. For many organizational developers interviewed in this study, this counterpower comes partly from connecting to the desires of both managers and employees for something new, something meaningful: salvation that reassures even as it provides deliverance to meaningful work.

These independent knowledge workers created networks and submersed themselves in these networks, but did not dissolve in them: their sense of identity in both their knowledge and their modus operandi was linked to a source of values and personal purpose located outside the organization. Indeed, they saw themselves as alternative, outside mainstream organizational practices of stagnancy and fragmented activity. These values, of course, are constituted within 
prevailing (some might say, middle-class, western) cultural discourses of 'authentic self' and 'meaningful work'. However, values are exercised by these knowledge workers in ways that grant them a certain freedom and control over their sense of identity, subject positions within/without the organization, and their work activity. It is worth noting that these individuals do not challenge fundamental structures of organizations, knowledge, or their own subjectivity. However, even as they embrace constraints, they remain network identities: fluid agents connecting people and ideas while resisting control - always moving, always working the "inbetween', to avoid capture.

\section{Conclusion and Implications for Organizations}

How can organizations enhance the contributions of these independent knowledge workers, informed by an understanding of their subjectivities? This question implies two aspects of enablement. On one hand, organizational conditions and management approaches might shift in ways more amenable to the working relations and identities of independently-minded knowledge workers, to encourage these innovative workers to not leave the organization in the first place. This does not mean locking such workers into place, but about conceiving work structures that allow far more open, independent movements and interactions. On the other hand, given increasing organizational reliance on contracted workers including independent knowledge workers, managers might find ways to better facilitate their integration toward enhancing both workers' satisfaction and their participation in organizational projects, routines and relations.

Presumably, these knowledge workers act in ways that organizations value: initiating innovation, creating connections, finding solutions, and adapting easily to change. If organizations do want to keep them from leaving in the first place, and the fact that these individuals did not seek independent careers until after many years as employees may well indicate their amenability to remaining in employment relationships, certain conditions might help. Their professed need for change and creative challenge, their skill in connecting/facilitating people and their preference for 'seeding' rather than 'managing' ideas suggests temporary project work arrangements. Their predilection to question policies, purposes and structures of activities suggests a need for flexible managers open to criticism and change. Their impatience with glacial bureaucratic processes and controlling policies suggests a need for managers who will 'block' for them: help to champion their ideas, find ways to cut red tape and jump hierarchies to help them link with appropriate teams. Yet these people are not usually free-wheeling maverick innovators eschewing organizational policy: they say they appreciate and even prefer boundaries, but need these to be clear and transparent. What they resist are managerial attempts to control their work: they need to negotiate the conditions and purposes of their activity, a human need which is surely not restricted to knowledge workers. The work patterns of such individuals no doubt may act upon organizational structures to open them even further, such that fluid networks, projects and temporary alliances - or at least organizational spaces protecting such configurations characterize connections and activity trajectories more than structures and classifications.

Organizations contracting with such individuals will enable better working relations by articulating clearer project purposes linked to organizational objectives, clear terms of contract activity, clear roles and clear expectations - a clarity that contractors say is often lacking. Indeed, this lack of clarity may result from the sorts of complexifying detail that obscures the manager's 
view, and that can be relieved in part through the outsider's perspective ${ }^{2}$. Integration of the contracted work with the organization's activity needs specific facilitation from managers: assisting the outsider to build relationships inside, and enabling concrete links between the contracted project and everyday organizational practice. This means coaching existing employees and opening their work in ways that allows the insertion and growth of new relationships and activity. Independent knowledge workers say they want to be partners with organizations in a development process, but that managers often treat them as solo solutions contracted to relieve them of an irritating problem.

Most of all, managers need to understand that knowledge is not a package delivered by a knowledge worker, whether from inside or outside the organization. Knowledge is dynamic, a moving active unpredictable flow that unfolds through new connections and relationships. Independent knowledge workers specializing in organizational change understand themselves as connectors, projecting a network identity that suggests their activity as generating and linking, not transmitting, knowledge. Organizations that can flexibly respond to and grow with these new connections not only may enable fuller satisfaction of knowledge workers but also closer integration of their participation with existing organizational networks of knowledge.

\section{References}

Alvesson, M. (2001) “Knowledge work: ambiguity, image, identity”, Human Relations, Vol 54 No 7, pp. 863-886.

Arthur, M. B. and Rousseau, D. M. (2000), "The boundaryless career as a new employment principle", in Arthur, M.B. and Rousseau, D.M. (Eds.), The Boundaryless Career, Oxford University Press. New York, pp. 3-20.

Barley, S \& Kunda, G. (2004), Gurus, Hired Guns and Warm Bodies: Itinerant Experts in a Knowledge Economy, Princeton University Press, Princeton.

Bird, A. (1996), "Careers as repositories of knowledge: considerations for boundaryless careers", in Arthur, M.B. and Rousseau, D.M. (Eds.), The Boundaryless Career, Oxford University Press, New York, pp. 150-168.

Brocklehurst, M. (2003), "Self and place: a critique of the boundaryless career", paper presented to the Critical Management Studies Conference, University of Lancaster.

Butler, J. (1992) 'Contingent foundations: feminism and the question of 'postmodernism'”, in Butler, J. and Scott, J.W. (Eds.), Feminists Theorize the Political, Routledge, New York \& London, pp. 3-21.

Casey, C. (2003) "The learning worker, organizations and democracy", International Journal of Lifelong Education, Vol 22 No 6, pp. 620-634.

Chappell, C., Rhodes, C., Solomon, N., Tennant, M. and Yates, L. (2003), Reconstructing the Lifelong Learner: Pedagogy and Identity in Individual, Organisational and Social Change, RoutledgeFalmer, London.

Cohen, L. and Mallon, M. (1999) "The transition from organisational employment to portfolio working: perceptions of boundarylessness", Work, Employment \& Society, Vol 13 No 2, pp. 329-352.

Davies, B. (2000), (In) scribing Body/Landscape Relations, AltaMira Press Walnut Creek.

\footnotetext{
${ }^{2}$ I am grateful to an anonymous reviewer for this particular point.
} 
Du Gay, P. (2004) “Against 'enterprise' (but not against 'enterprise' for that would make no sense”, Organisation, Vol 11 No 1, pp. $37-57$.

Fenwick, T. (2003) "Flexibility and individualisation in adult education careers: the case of portfolio workers", Journal of Education and Work, Vol 16 No 2, pp. 165-184.

Fenwick, T. (2004) "Learning in portfolio work: anchored innovation and mobile identities", Studies in Continuing Education, Vol 26 No 2, pp. 229-241.

Foucault, M. (1988), “Technologies of the self”, in Martin, L., Gutman, H., and Hutton, P.

(Eds.), Technologies of the Self, Tavistock, London.

Foucault, M. (2003), Society must be Defended, Penguin Press, London.

Gee, P., Hull, G., and Lankshear, C. (1996), The New Work Order: Behind the Language of the New Capitalism, Westview Press, Boulder, CO.

Gold, M. and Fraser, J. (2002) "Managing self-management: successful transitions to portfolio careers", Work, Employment and Society, Vol 16 No 4, pp. 579-598.

Hey, V. (2002) "Horizontal solidarities and molten capitalism: the subject, intersubjectivity, self and the other in late modernity", Discourse: Studies in the Cultural Politics of Education, Vol 22 No 2, pp. 226-241

Hughes, K. D. (2001), Self-Employment, Skill Development and Training in Canada: Working paper (Cat. No. MP32-28/01-12-1E), Hull, Quebec, Canada: Applied Research Branch HRDC.

Industry Canada (2006), Key Small Business Statistics (Cat. No. Iu1-9/2005-2E, January 2006). Retrieved February 9, 2006 from http://www.strategis.gc.ca/sbstatistics

Rose, N. (1998), Inventing Ourselves, Polity Press, Cambridge.

Sullivan, S. E. (1999) "The changing nature of careers: A review and research agenda", Journal of Management”, Vol 25 No 3, pp. 457-484.

Storey, J., Salaman, G., and Platman, K (2005) "Living with enterprise in an enterprise economy: freelance and contract workers in the media", Human Relations, Vol 58 No 8, pp. 1033 - 1054

Taylor, C. (1989), Sources of the Self: The Making of Modern Identity, Harvard University Press, Cambridge, MA.

Zizek, S. (1999), The Ticklish Subject: The Absent Centre of Political Ontology, Versa, London, UK; New York.

\section{Acknowledgements}

This article is based on a portion of a three-year project 2002-2005 funded by the Social Sciences and Humanities Research Council of Canada.

I am grateful to the comments of anonymous reviewers, whose suggestions have helped strengthen the article considerably. 